\title{
EL MUNDO CORTESANO DE JUAN II A ESCENA
}

\author{
María Ceide RodRíguez \\ Universidad de Vigo
}

\begin{abstract}
RESUMEN
El presente trabajo centra su atención en Los cortesanos de don Juan II, obra del escritor vallisoletano Jerónimo Morán. Este drama histórico, estrenado en 1838 como respuesta contraria del autor a la guerra carlista que en ese momento se libra en España, toma como argumento literario los entresijos palaciegos que en 1453 vive la corte del rey Juan II de Castilla. Para transmitir su rechazo a las formas de gobierno vinculadas al Antiguo Régimen, Morán se sirve teatralmente de una extensa nómina de personajes, a menudo con un referente histórico reconocido, a través de los cuales trata de adoctrinar al público decimonónico en la necesidad de cuestionar determinadas actitudes políticas y de reflexionar acerca del infortunio que conlleva el ansia irracional de poder.
\end{abstract}

PALABRAS ClAVE: J. Morán, drama histórico romántico, Álvaro de Luna, liberalismo.

\section{Abstract}

The present work concentrates its attention on Los cortesanos de don Juan II, work of the writer Jerónimo Morán. This historical drama, premiered in 1838 as the author's opposite response to the Carlist war that is currently being fought in Spain, takes as a literary argument the palatial insights that in 1453 the court of King Juan II of Castilla is living. In order to express the rejection of the forms of government linked to the Old Regime, Morán uses a dyeing of an extensive list of characters, often with a recognized historical reference, through which he tries to indoctrinate the nineteenth-century public in the need to question certain political attitudes and to reflect on the misfortune that accompanied the irrational craving for power.

KEY WORDS: J. Morán, romantic historical drama, Álvaro de Luna, liberalism.

El teatro español y sus autores encuentran en el drama histórico ambientado en el pasado medieval el molde adecuado para la expresión de sus ideas e impresiones sobre el mundo que los rodea. En este sentido, cobran especial relevancia las reescrituras que la dramaturgia decimonónica lleva a cabo de los conflictos políticos de la corte Recibido: 30-06-2017 / Aceptado: 02-08-2017 
castellana del rey Juan II, encarnados con frecuencia en el personaje de Álvaro de Luna, condestable y hombre fuerte del reino en la primera mitad del siglo xv. Un significativo ejemplo de ello lo constituye el drama Los cortesanos de don Juan II (1838-1839), obra del vallisoletano Jerónimo Morán de la que voy a ocuparme en las páginas que siguen².

Tal y como afirma Guillermo Carnero, las turbulencias políticas que atenazan a España durante los primeros años del siglo XIX dan lugar a una cuantiosa producción ideológica que «en el ámbito del teatro no ha sido debidamente estudiada ni catalogada ${ }^{2}$. Tal es el caso de la pieza a la que acabo de referirme. Escrita en 1838, al abrigo de una serie de acontecimientos históricos y como medio de denuncia política, prácticamente no existen referencias críticas a la obra ni tampoco a su autor.

Apenas conocido en la actualidad, Jerónimo Morán Martín (1817-1872) es, en el siglo XIX, un reconocido político e intelectual de su tiempo. Formado durante su juventud en la Academia de Letras Humanas de la Universidad de Valladolid, su ciudad natal, en este espacio, que comparte con otras ilustres personalidades románticas como José Zorrilla o Miguel de los Santos Álvarez, pronto se revela al mundo como joven promesa literaria ${ }^{3}$. Tal y como recoge el Eco del Comercio en su número $1863^{4}$, con tan solo veinte años, en 1837, es premiado con un rasgo épico por la Sociedad Económica del País de Salamanca gracias a uno de los textos que escribe sobre el sitio de Bilbao ${ }^{5}$. Trasladado ya a Madrid, en la capital trabaja durante años como funcionario en los Ministerios de Guerra, Hacienda y Fomento, al tiempo que ejerce la abogacía y cultiva su faceta literaria ${ }^{6}$. Luego de colaborar activamente en periódicos de reconocido prestigio como Semanario Pintoresco Español, Guardia Nacional, El Artista o La Risa, el 1 de enero de 1867 funda junto a Vicente Olivieras Biec, profesor de los Estudios Católicos de Madrid, la revista La Guirnalda. A través de esta publicación, de perfil conservador y dirigida eminentemente a un público femenino, presentará a los lectores decimonónicos su propia y variada producción literaria entre la que es posible destacar sus dramas,

\footnotetext{
${ }^{1}$ Este trabajo se inserta en el ámbito investigador del proyecto FFI-2015-64107-P (MINECO/FEDER, UE).

${ }^{2}$ G. Carnero, «Temas políticos contemporáneos en el teatro español de los primeros años del siglo XIX», en Ermanno Caldera (ed.), Teatro Politico Spagnolo del Primo Ottocento, Roma, Bulzoni, 1991, aquí p. 19.
}

${ }^{3}$ N. Alonso Cortés, Antología de poetas vallisoletanos modernos, Valladolid, Biblioteca Studium, 1914, p. 57.

${ }^{4}$ En el número del 27 de febrero de 1839 se menciona el premio concedido a Morán y se informa a los lectores acerca de la posibilidad de adquirir la obra al precio de dos reales en la librería de Escamilla.

${ }^{5}$ Destaquemos, en este sentido, el interés que este hecho despierta entre los escritores de la época. Uno de ellos es el también joven Antonio García Gutiérrez, que en 1837 publica El sitio de Bilbao, «drama de circunstancias en dos actos, en prosa y verso» (Madrid, Imprenta de Yenes).

${ }^{6}$ M. Ribao Pereira, «Prensa, actualidad y romanticismo español: el caso de Jerónimo Morán y la corte de Juan II de Castilla», Culture pour tous. Le rôle des médias dans la vulgarisation des savoirs, en I. Rodríguez Moranta y D. Thion, (eds.), Monográfico de Amnis. Revue de Civilisation Contemporaine Europes/Amériques, 14 (2015). 
comedias y zarzuelas 7 . Será, no obstante, una biografía, Vida de Miguel de Cervantes Saavedra, un texto incluido en una lujosa edición de El Quijote publicada en la época ${ }^{8}$, a la que deba, en realidad, la mayor parte de su reconocimiento público.

Las circunstancias y los avatares políticos del momento que le toca vivir justifican buena parte de su escritura, como puede observarse en Los cortesanos de don Juan II, en donde el autor trata de plasmar la convulsa situación gubernamental que vive la España de su tiempo ${ }^{9}$. La guerra carlista, que enfrenta a los partidarios del infante don Carlos y a los de la princesa Isabel por el trono de España, contextualiza esta obra que Morán escribe expresamente para ser representada en una función benéfica a favor de los prisioneros del bando cristino tras su derrota en Maella. El estreno tiene lugar el 29 de diciembre de $1838^{10}$ y el éxito de su recepción será el que motive que en los meses de julio y agosto de 1839 salga a la luz Alfonso Pérez de Vivero. Leyenda castellana del siglo $X V$, el cuento que Morán elabora para la revista El Panorama tomando como hipotexto el documento dramático. No es mi propósito analizar aquí las características del relato en cuestión, pero sí me parece conveniente señalar que ni este texto ni tampoco la reimpresión que del mismo se lleva a cabo en 1870 para La Guirnalda ${ }^{11}$ constituyen simples adaptaciones del drama inicial; en ellas Morán introduce significativos cambios de forma y contenido que alteran el sentido del texto y que dan cuenta del propio devenir ideológico del autor quien, desde un posicionamiento liberal, manifestado en sus inicios y con el que muestra su rechazo al poder absolutista representado por la figura del infante don Carlos, se desplaza hacia posturas claramente conservadoras de las que hace gala en los textos que publica en su vejez y a los que da cabida en su periódico, como ya he mencionado, de marcado perfil moderado.

El estreno en Valladolid de Los cortesanos de don Juan II se efectúa precedido de ¡Un liberal!, «drama en un acto basado en un episodio de la historia de la revolución francesa, puesto por primera vez en escena en el teatro del Príncipe el 6 de julio de 1835

\footnotetext{
${ }^{7}$ M. Ceide Rodríguez, «El Romanticismo y la recuperación de la materia medieval: el caso de J. Morán», Nuevas perspectivas literarias y culturales (I CIIELC), en R. Hernández Arias, G. Rivera Rodríguez, S. Cuba López y D. Pérez Álvarez (eds.), Vigo, MACC-ELICIN, 2016, aquí p. 4.

${ }^{8}$ Volumen editado por José Gil Dorregaray en la Imprenta Nacional de Madrid entre los años 18621863. Adornado con láminas de cobre y facsímiles de Cervantes, en su tercer tomo se incluye el trabajo de Morán elaborado a partir de un estudio anterior de Fernández de Navarrete (A. Rey Hazas y J. R. Muñoz Sánchez, El nacimiento del cervantinismo: Cervantes y el Quijote en el siglo XVIII, Madrid, Verbum Editorial, 2006, p. 56).

${ }^{9}$ M. Ribao Pereira, «Prensa, actualidad y romanticismo», art. cit., p. 14.

${ }^{10}$ M. Ribao Pereira, «Una relectura romántica de la corte: Los cortesanos de don Juan II, de Jerónimo Morán», en J. M. González Herrán et al., (eds.), La historia en la literatura del siglo XIX. Actas del Coloquio de la Sociedad Española del Siglo XIX, Barcelona, Universitat de Barcelona, 2017, pp. 651- 660, aquí p. 652.

${ }^{11}$ El Panorama, 18 de julio (1839), pp. 42-45; 25 de julio (1839), pp. 61-63; 1 de agosto (1839), pp. 75-76. La Guirnalda, 16 de diciembre (1869), pp. 381-382; 1 de enero (1870), pp. 3-5; y 16 de enero (1870), pp. 11-12.
} 
y traducido por Carlos García Doncel» ${ }^{12}$. Este texto forma parte de la función benéfica que explica la redacción misma de la obra de Morán y su reivindicación anticipa el alegato antiabsolutista de la pieza a la que precede; no hay que olvidar que tras el Abrazo de Vergara se publican en la época tres dramas liberales: el de Morán, el de Bonilla, Don Álvaro de Luna, condestable de Castilla, y el de Gil y Zárate, Don Álvaro de Luna. El simple hecho de que textos de esta temática e ideología se lleven a escena en un momento político tan delicado supone ya toda una declaración de intenciones, pero en el caso de Los cortesanos de don Juan II el cariz reivindicativo que denuncia el anticarlismo y el rechazo al poder absolutista resulta, además, especialmente explícito, como tendré ocasión de demostrar.

El argumento de la pieza presenta el juego de intrigas que en el siglo XV se produce en la corte castellana a raíz de los excesos en el gobierno que el condestable, don Álvaro de Luna, principal valedor del monarca Juan II, lleva a cabo en perjuicio de la nobleza y clase dirigente del reino que, alarmada por la pérdida de poder, busca su caída. Según el planteamiento dramático, será el comportamiento de su sobrino y yerno, Juan, el que desencadene no solo la muerte de don Álvaro sino también la del contador Alfonso Pérez de Vivero, futuro marido de doña Jimena y acérrimo enemigo de los Luna. A lo largo de la obra, el enredo original que presenta los amores de la pareja y los irreprimibles celos de don Juan se entrecruza deliberadamente con la trama política que describe las claves y condiciones en las que se orquestan las intrigas cortesanas que evidencian los intereses de los distintos bandos reconocidos en el texto. En consonancia con la estética romántica, ambos asuntos degeneran progresivamente con el desarrollo de los acontecimientos y determinan el fracaso final de la mayor parte de sus protagonistas, en especial la de su héroe.

Las acciones se desarrollan en Burgos durante la Semana Santa de 1453 y recrean, como acabo de apuntar, un acontecimiento histórico real acaecido durante ese período: la caída en desgracia del condestable como consecuencia del crimen perpetrado contra el contador ${ }^{13}$. Los paisajes nocturnos, como el que sirve de escenario en la ejecución de Alfonso y de los que dan cuenta las oportunas acotaciones («La escena estará escasamente iluminada por la sola luz de una lámpara: el interior está casi a oscuras. Tres asientos estropeados» [IV, 1, p. 59]), las ruinas, representadas por la inhabilitada y desmantelada torre del alcázar de don Álvaro,

El teatro representa el interior de una torre ruinosa y desmantelada en el alcázar del condestable. (IV, 1, p. 59).

\footnotetext{
${ }^{12}$ M. Ribao Pereira, «Una relectura romántica de la corte: Los cortesanos de don Juan II, de Jerónimo Morán», ob. cit., p. 652.

${ }^{13}$ En adelante, cito el drama (acto en romanos y escena en arábigos) por su primera edición. J. Morán, Los cortesanos de don Juan II, drama histórico original en cuatro actos y variedad de metros, Madrid, Repullés, 1839.
} 
RIVADENEIRA:¿Tenéis por eso temor

de que pueda ver la gente

la maniobra desde el puente

a través del resplandor?

¿No sabéis de noche el miedo

que al pueblo inspira esta torre,

pensando que la recorre

la hechicera de Toledo?

Si pasa alguno, se asombra

y pide a Dios protección

como vea en el torreón

nuestros bultos o su sombra.

(IV, 1, p. 59),

así como lo lúgubre y funesto de determinadas situaciones que anticipan un final aciago,

JuAn: Por más que tú digas, crece

en mi pecho la inquietud.

RivADENEIRA: ¿Tembláis, señor?

JuAn: Tiemblo, sí:

Penetra mi cuerpo un frío...

(IV, 1, pp. 59-60),

perfilan a lo largo de toda la obra, y especialmente en el último de sus actos, una atmósfera medieval recreada con frecuencia por los escritores románticos y muy del gusto del receptor decimonónico hasta, cuando menos, el segundo tercio del siglo XIX ${ }^{14}$. $Y$ es que durante este período, especialmente en las décadas de los años 30 y 40, los autores buscan deliberadamente dotar a sus obras de un exotismo, también temporal, que encuentran rescatando la «idealizada Edad Media, cristiana y caballeresca» como caladero fundamental para la recuperación de temas y argumentos para sus obras ${ }^{15}$. De ahí que buena parte de la producción literaria de esta época la constituyan dramas de temática histórica como el que me ocupa.

Todas las intrigas palaciegas, forjadas en el seno mismo de la corte, se ejecutan al abrigo de las intenciones e intereses personales de una amplia red de personajes secundarios sin los cuales ninguna de ellas llegaría a efectuarse en los términos en los que se producen en el drama. Para configurar el clima de anarquía política que Morán pretende presentar a los espectadores como metáfora de su propio tiempo, recurre a una extensa nómina de secundarios que, en estricto orden de aparición, son los que siguen: Jimena, Chacón, don Juan de Luna, los condes de Haro y Plasencia, Fernando

\footnotetext{
${ }^{14} \mathrm{M}$. Ribao Pereira, Textos y representación del drama histórico en el romanticismo español, Pamplona EUNSA, 1999.

${ }^{15}$ C. Mata Induráin, «Los dramas históricos de Gertrudis Gómez de Avellaneda» El drama histórico. Teoría y comentarios, en Kurt Spang (ed.), Pamplona, EUNSA, 1998, pp. 193-213, aquí 193.
} 
Rivadeneira y el fraile dominico.

La única mujer con un significativo peso dramático en el texto abre la obra que se inicia de manera directa e inmediata. Morán introduce al lector en el imaginario de una historia que comienza in medias res con un diálogo que doña Jimena mantiene con Laura, su camarera, a propósito del malestar que la vida en la corte le produce:

LAURA: ¿Ello es, señora, que al fin

estáis aquí más serena?

Jimena: Algún alivio a mi pena

encuentro en este jardín:

en él, Laura, fácilmente

se aplacan mis amarguras,

$[\ldots](\mathrm{I}, 1, \mathrm{p} .5)^{16}$.

Jimena es, como digo, el personaje femenino principal. Dama de la reina, al comienzo del drama se descubre ya la nobleza de su linaje, el heroísmo de su padre muerto en Olmedo y, por tanto, su condición de huérfana aquejada de una tristeza y desdicha ilimitadas. Extremadamente pasiva en sus acciones, reúne muchas de las cualidades que caracterizan a los personajes representados por mujeres en la literatura romántica.

Llama la atención el contraste que parece existir entre la imagen que la joven percibe de sí misma y la que proyecta sobre los demás. A ojos de los diferentes miembros de la corte, Jimena concentra en su persona todas las virtudes a las que puede aspirar una muchacha del siglo XIX. Querida y adorada por los reyes, deseada por los hombres y envidiada por las mujeres no se considera, sin embargo, una persona feliz, pues adolece de la nostalgia y la melancolía propias de quien ha sufrido grandes pérdidas (a la ausencia de su progenitor viene a sumarse la de su amado Vivero, a quien considera caído en combate tras su participación en la batalla de Navarra); esta sensación, premonitoria, de la que conseguirá desembarazarse en momentos concretos de la obra, la acompañará, sin embargo, hasta el desenlace de la misma, donde vivirá en su propia piel la crudeza de su sino.

El diálogo en el que expresa a Laura el ánimo que la invade tiene lugar en un lugar clave en el drama: los jardines de palacio. Tal y como apunta Catalán Marín ${ }^{17}$, este espacio, en el que se desarrolla por entero el primer acto, será testigo del acontecimiento

\footnotetext{
${ }^{16}$ A la hora de citar ejemplos adecuo su ortografía a la norma actual, pautada por la Real Academia Española en la edición más reciente, la vigésimo primera, de su Diccionario. De acuerdo con ello, regularizo el uso de las grafías $\mathrm{g} / \mathrm{j}, \mathrm{b} / \mathrm{v}, \mathrm{i} / \mathrm{y}, \mathrm{h}$, el empleo de signos de interrogación y exclamación al principio y al final de la oración, así como la acentuación gráfica de las palabras.
}

${ }^{17}$ M. S. Catalán Marín, La escenografía de los dramas románticos españoles (1834-1850), Zaragoza, Prensas Universitarias de Zaragoza, 2003, p. 162. 
fundamental a partir del cual se desencadena la acción en torno a la que pivotan las dos tramas a las que me he referido ya. Aquí Jimena alivia sus penas entregándose a la placidez del sueño como vía de escape a sus pulsiones internas; en ese estado la encontrará Vivero quien, luego de presenciar agazapado el agravio de don Juan, se enfrentará a él para defender el honor de la dama. También en los jardines, el monarca comunicará a don Álvaro la urgencia de su destierro como condición inexcusable para el cese de las revueltas en el reino y don Juan maquinará el plan de venganza dispuesto contra los amantes.

Tal confabulación, que busca no solo la caída del contador sino también la de la propia Jimena, llegará a buen puerto gracias a la actuación de Chacón, hasta entonces fiel y leal sirviente de Alfonso. Poco se sabe dramáticamente de este personaje, cuya participación en el drama parece, a priori, anecdótica. Su intervención en la trama amorosa resulta, sin embargo, fundamental, pues motivado por intereses económicos se dejará engañar por Rivadeneira, criado de don Juan, para conseguir llevar a Jimena hasta el alcázar en el que tendrá lugar el asesinato de Vivero. Este hecho marcará el desenlace del drama en el que la joven, entonces sí, invadida por el espíritu de una verdadera heroína romántica, vengará la muerte de su amado acabando con la vida de don Juan al que apuñalará, una única y certera vez, con su propia arma.

El sobrino y yerno de don Álvaro es, como he apuntado, quien propicia la caída del contador. Al igual que la figura histórica a la que representa (muestra del buen trabajo de documentación del autor) este personaje, casado con María de Luna, hija ilegítima del condestable, ostenta, gracias a su filiación, cargos de cierta notoriedad en Castilla $^{18}$. Mezquino, frío y calculador, su maldad se exhibe claramente en el texto en donde, habiéndose concertado el matrimonio entre Vivero y Jimena y cegado por el orgullo,

JuAN: $[\ldots]$ ¿Has visto hombre más desgraciado que yo...? ¿No escuchaste que el rey quiere que en su nombre sea padrino en el enlace de la orgullosa Jimena con mi rival detestable? (II, 8, p. 33),

no duda en intrigar contra su tío poniendo en práctica su lema «paciencia y mala intención» (II, 8, p. 34) para evitar verse arrastrado por su caída y para conseguir acabar con la vida de su rival,

JUAN: Bien lo sé, tú adivinaste

\footnotetext{
${ }^{18}$ M. Ribao Pereira, «Una relectura romántica de la corte: Los cortesanos de don Juan II, de Jerónimo Morán», ob. cit., p. 656.
} 


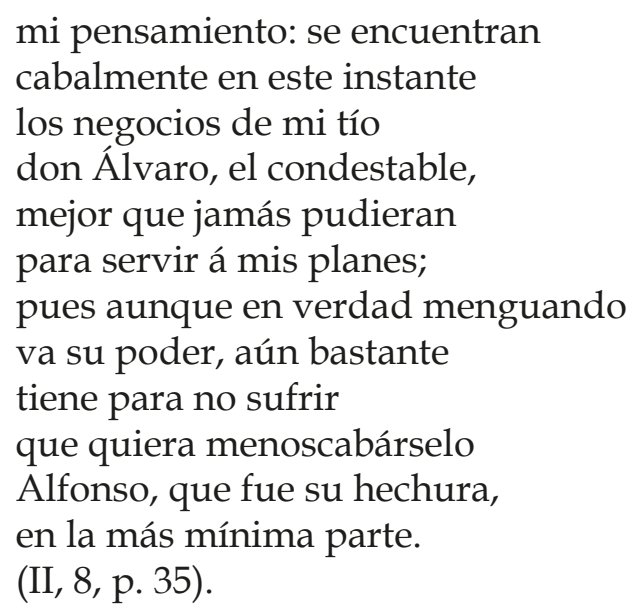

El plan de venganza lo urde junto a su paje Fernando Rivadeneira; de orígenes humildes y ayudado por don Juan en sus inicios en la corte, el sirviente es uno de los personajes que mayores cotas de mezquindad alcanza en el drama llegando incluso a afirmar de sí mismo «solo sirvo para intrigas» (IV: 1,61). La fidelidad y generosidad con la que supuestamente actúa en favor de su señor en un primer momento contrasta con el comportamiento interesado del que hace gala a continuación cuando, sin reparos, se muestra dispuesto a desvelar las claves de la conjura orquestada por don Álvaro y su sobrino a cambio de la obtención de ciertos privilegios personales. En estos términos se refiere a su señor cuando reconoce el poder de manipulación que ejerce sobre él,

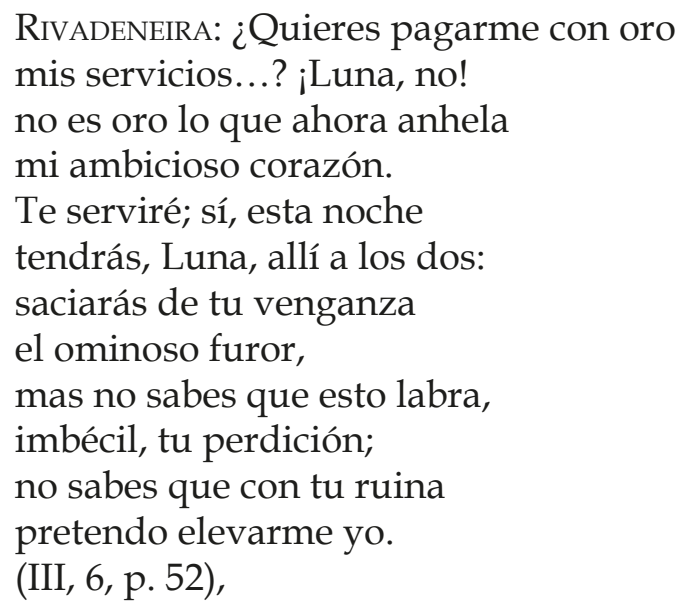

y de esta manera revela los detalles de la conspiración a los condes de Haro y Plasencia,

RIVADENEIRA: Muerto Vivero, don Álvaro muere de cierto también.

Plasencia: Ya lo oís, Haro: esta noche asegurado veréis nuestro triunfo. (III, 8, p. 55).

Los nobles conforman un personaje dual y simbolizan las dos caras de una 
misma moneda. Junto con don Álvaro, son los protagonistas fundamentales de la trama política a la que viene a subordinarse la amorosa desde el momento en el que consienten su participación en la confabulación dispuesta por Rivadeneira y don Juan.

Principales representantes de los intereses del príncipe Enrique, acérrimo enemigo de don Álvaro, persiguen, como digo, un mismo objetivo: la caída del condestable como puerta de acceso directo a la gobernabilidad del reino y a su propio enaltecimiento. Ambos ven en la figura del valido un obstáculo para el progreso de la nobleza castellana y ambos acusan a Luna de ejercer un poder abusivo en la corte y de explotar su cargo y su posición al lado del rey para manipular sus decisiones en su favor y obtener, de esta manera, múltiples prebendas y beneficios personales,

PLASENCIA: Jamás traidores seremos, orgulloso condestable; vuestro yugo abominable solo quebrantar queremos. ¿Os parece buena ley que os ciñáis vos la corona, tirano de la persona y los estados del rey? ¿Os parece bien, por Dios, que inclinada la cabeza tenga siempre la nobleza dónde estuviéredes vos? [...]. HARO: Tiene sobrada razón ahora el conde de Plasencia: harto tiempo con paciencia sufrimos tanto baldón. (II, 1, pp. 24-25).

Sin embargo, también ellos son acusados por el propio don Álvaro de idéntica conducta. Ante el monarca, el condestable recrimina a los nobles su anhelo de poder y sus deseos ajenos al bien común:

Alvaro: Cuando la altiva grandeza alzando rebelde grey, osó de su mismo rey amenazar la cabeza, entonces, rey, recordad quien fue el vasallo primero que esgrimió por vos su acero y os volvió la libertad.

Ved quien alza en vuestra tierra los bandos y las facciones; quien enciende las pasiones y las incita a la guerra.

$Y$ en fin, mirad que la envidia y la sed de ambición, 
con máscara de adhesión

quieren cubrir su perfidia.

(II, 2, pp. 27-28).

La irritación y turbación que Juan II siente frente a los planteamientos de unos y de otros podría representar a la perfección la sensación de desconcierto que, de seguro, el público decimonónico experimentó a finales de la década de los treinta ante la pugna mantenida entonces entre los partidarios del infante don Carlos y los defensores de Isabel como heredera al trono de Castilla. Los intereses políticos enfrentados de los diferentes miembros de la corte provocan, al igual que el conflicto dinástico que contextualiza la representación del drama en el XIX, una grave inestabilidad social, gubernamental y económica cuyos efectos sufre en su inmensa mayoría el pueblo, que ve cómo los escasos recursos del reino son invertidos en una guerra absurda, librada entre sus propios dirigentes y que, previsiblemente, solo traerá nefastas consecuencias para todos.

El papel de los condes en la contienda resulta esencial. Su disposición para recuperar el poder usurpado por don Álvaro y su firme determinación de alejar al condestable de la corte los lleva a participar activamente en la intriga ideada por Rivadeneira. Sin embargo, la naturaleza de sus caracteres, radicalmente opuestos, les impide converger en cuanto a la metodología planteada para la ejecución del plan se refiere. Cuando el momento de la verdad se acerca, el conde de Plasencia, mucho más visceral, impulsivo y pasional que su duplo, manifiesta abiertamente su voluntad de sacrificar la vida de Alfonso como obligada exigencia para la consecución efectiva de sus objetivos, pues, a raíz de un diálogo mantenido con el joven en el segundo de los actos y en el que el contador rehúsa posicionarse a favor de uno u otro bando, el conde pasa a considerarlo una seria amenaza para los intereses que persigue:

Plasencia: ¿De qué bando sois vos?

VIVERO: ¿Yo? De ninguno

Plasencia: De alguno de los dos justa es la causa.

VIVERO: De gratitud me ligan fuertes vínculos

al señor condestable: allá en Navarra

también quedé obligado con el príncipe:

ser imparcial me toca.

PlasenCIA: Eso no basta;

a su lado o al nuestro: el reino todo

de sufrir a don Álvaro se cansa.

(II, 5, p. 30).

El de Haro, en cambio, observador racional e intuitivo de los acontecimientos, respalda la caída del condestable, pero apoyado en unos sólidos principios morales, cuestiona con vehemencia la necesidad de dar muerte a un inocente. Este hecho supone el distanciamiento definitivo de los nobles que ya con anterioridad habían hecho 
patentes sus desavenencias cuando, encontrándose en el interior la iglesia mayor de Burgos, la actitud irrespetuosa del de Plasencia, que se jacta de no dormirse pese a lo aburrido del sermón, indigna al conde de Haro, que censura su conducta en lugar sagrado (III, 1, pp. 40-42).

En este espacio, la iglesia, desarrolla su actividad el fraile dominico. Al igual que don Juan de Luna y los condes, amén de los ya conocidos Álvaro de Luna y Alfonso Pérez de Vivero, el personaje del religioso representa una figura histórica reconocida. Entre las fuentes de las que los escritores románticos beben para acercarse a la historiografía del tiempo de Juan II muy probablemente se encuentran las interpretaciones que Quintana y el Padre Mariana, entre otros, realizan de las crónicas elaboradas en la Edad Media sobre Álvaro de Luna. Es posible que Morán se aproximase en su momento a la edición de la Crónica del Condestable redactada en 1784 por Josef Miguel de Flores ${ }^{19}$ para documentarse acerca del episodio que tiene lugar en el templo y en el que el fraile dominico desempeña una labor muy importante. En este trabajo el historiador gaditano da cuenta de la existencia de un fraile de la Orden de los Predicadores que el día del Viernes Santo pronuncia ante sus fieles un discurso en el que critica duramente los métodos y actitudes del Maestre de Santiago a quien acusa, aunque de manera velada, de ser el causante de buena parte de los problemas que azotan y convierten al reino en un hervidero político e institucional ${ }^{20}$.

En el drama, el religioso se erige también como confesor de doña Jimena y, sobornado por Rivadeneira, arenga a los asistentes al sermón en contra de don Álvaro quien, enfurecido, busca su muerte inmediata. Don Juan consigue aplacar su ira y convencerlo de la culpabilidad del enemigo común que los une, Vivero, a través, de unas cartas, supuestamente escritas por la dama y dirigidas al religioso, que prueban la responsabilidad del contador como ideólogo último de la afrenta pública ejecutada por el fraile y sufrida por el condestable.

Estos papeles, a los que el valido concede total credibilidad, junto con las falsas notas inculpatorias teóricamente redactadas por Alfonso (en realidad, cuidadas imitaciones de su letra), así como el pliego con el que Jimena es citada en la torre en el último de los actos («aborrecido papel» en palabras de Alfonso [IV, 4, p. 71]), forman parte de una de las estructuras que, tomadas de la narrativa histórica de la

\footnotetext{
${ }^{19}$ Puede consultarse la publicación completa en el portal de la Hemeroteca Digital de Castilla y León: https:/ / bibliotecadigital.jcyl.es/es/consulta/registro.cmd?id=4544 [consultado 04-04-2017].

${ }^{20} \mathrm{~J}$. M. de Flores Barrera (1784), Cronica de D. Alvaro de Luna, Condestable de los Reynos de Castilla y de Leon, Maestre y Administrador de la Orden y Caballeria de Santiago, Madrid, Imprenta de D. Antonio de Sancha, 1784, pp. 305-306.
} 
época, están presentes en los dramas del siglo XIX ${ }^{21}$. La presencia de prendas y objetos simbólicos como las capas y embozos de algunos de los personajes en determinadas escenas (Vivero en I, 10, p. 21; don Álvaro, don Juan y Rivadeneira en III, 2, p. 42), así como las cartas a las que acabo de referirme y a través de las que se gesta el complejo juego de intrigas palaciegas, dan cuenta de los continuos trasvases que en la literatura decimonónica se producen entre narrativa y teatro y ponen de manifiesto la cuidada pulcritud literaria del autor en la escritura de la pieza y en la construcción de todos y cada uno de sus personajes.

La astucia de Rivadeneira, principal cerebro de la trama, se revela especialmente viva en la elección de los colaboradores en la confabulación. El sirviente de don Juan elige al fraile a sabiendas de la inmunidad de la que goza ante el monarca a causa de su condición de «ministro del señor» (III, 5, p. 49); el criado se sabe protegido ante cualquier tipo de filtración, pues el cargo del dominico garantiza que este no será ajusticiado a pesar del revuelo causado y, por tanto, ni él mismo ni don Juan serán delatados. La designación de los condes, por su parte, le permite rentabilizar la pugna mantenida por las distintas parcialidades que incendian el reino; en ellas ve Rivadeneira la oportunidad perfecta para ejecutar con éxito su elaborado plan de encumbramiento: la caída de los Luna traerá consigo un vacío de poder que supondrá su ascenso inmediato a las más altas dignidades.

Ahora bien, que los principales representantes de las clases política y eclesiástica accedan a participar en una intriga palaciega de tal magnitud, en la que no solo se ponen en juego intereses económicos y materiales sino en la que se llega incluso a especular con la vida de inocentes, revela la existencia de un nocivo entramado de corrupción a todos los niveles a través del que Morán busca retratar el descompuesto panorama institucional de su época. La negativa configuración de todos los estamentos representados en el texto sirve al autor para dibujar un tiempo turbio y anárquico al que comparar con el suyo propio ${ }^{22}$. A través del drama, el autor manifiesta su rechazo inapelable a la fragilidad de una monarquía que, lejos de erigirse como luz guía del reino y de representar a la pluralidad de su pueblo, actúa a ciegas sin valorar las consecuencias de sus decisiones. Tampoco admite Morán el comportamiento de las altas esferas cuyo único desvelo lo constituye el deseo de poder ilimitado; reprueba también con dureza la inclinación de un clero preocupado exclusivamente por la acumulación de riquezas y enjuicia de manera muy negativa las perversas aspiraciones de algunos sectores poco formados para el cargo al que aspiran.

\footnotetext{
${ }^{21}$ C. Mata Induráin, ob. cit., p. 204.

${ }^{22}$ M. Ribao Pereira, «Una relectura romántica de la corte: Los cortesanos de don Juan II, de Jerónimo Morán», ob. cit., p. 653.
} 
A lo largo de la obra, se suceden con frecuencia las críticas a las máximas del «todo vale» $\mathrm{y}$ «el fin justifica los medios» enarboladas por prácticamente todos los personajes del texto. Tales axiomas, sobre los que los principales implicados en la contienda sustentan sus respectivos planes de conjura, aparecen perfectamente ejemplificados en el fragmento en el que el conde de Plasencia trata de convencer al de Haro, aunque sin éxito, de la necesidad de dar muerte a Vivero:

Plasencia: [...] Pero decidme, el de Haro, ¿acaso preferiréis por salvar la vida a un hombre sacrificar las de cien? (III, 8, p. 56).

La negativa del más racional de los nobles a participar en semejante despropósito no disuade a su par, que dejará patente su sanguinario carácter al colaborar en el engaño orquestado contra el contador.

También censura el autor, en repetidas ocasiones y de manera lo suficientemente explícita para el público de la época, la ambición desmedida y la impunidad con la que la clase dirigente comete crímenes y desencadena batallas a todas luces innecesarias que solo buscan el beneficio propio de quienes las libran. En el tercer acto y a través del conde de Haro, contrapunto de cordura al caótico universo de egos contenidos en la corte, manifiesta su rechazo a la violencia como herramienta política y, en clara referencia al conflicto desencadenado por el infante don Carlos, critica la actitud de quien se cree con derecho a gobernar a cualquier precio:

HARO: Estoy pasmado de oíros:

tenéis ancha la conciencia

por demás.

Plasencia: ¿Quién no la tiene

en circunstancias como estas?

HARO: ¿Habéis hoy perdido el juicio?

Me gusta la consecuencia.

¿Conque, porque se halle el reino

combatido por opuestas

ambiciones, será bien

que los fieles no lo sean?

(III, 1, p. 41).

Con este análisis, Morán trata de aleccionar a los asistentes a la representación en el rechazo al posicionamiento político absolutista que se aleja del pueblo y que, de manera consciente en el ejercicio de su actividad, busca únicamente la consecución de sus objetivos a costa del bien común.

Esta crítica liberal, patente desde las páginas iniciales de la obra, se hace 
inequívocamente explícita en el cuarto y último de sus actos. El desenlace del drama, en el que confluyen las tramas política y amorosa, tiene lugar, de acuerdo con la simbología romántica y con el gusto por la Edad Media, en las dependencias de un castillo, el de don Álvaro, como «símbolo del poder medieval y de la opresión» ${ }^{23}$. Así describen Rivadeneira y don Juan el espacio en el que se perpetra el crimen en la noche del Viernes Santo. Cuatro hombres de armas ejecutan, lanzando al vacío desde el más alto torreón, al contador del rey:

JuAN: Habrás visto en el alcázar

de mi tío un torreón

elevadísimo...

RIVADENEIRA: Sí,

tiene al sur un corredor

que está amenazando ruina.

Juan: Pues después de la oración

allí se hará el sacrificio.

(III, 5, p. 49).

La manera en la que el joven Alfonso encuentra la muerte y la verticalidad del decorado de esta escena podrían relacionarse directamente con la imagen romántica del ángel caído, iconografía frecuentemente rentabilizada por los escritores del xix que representa la lucha del ser humano contra Dios, en este caso, contra su sino. Pero no solo el contador del rey halla en el drama un final desgraciado. De una forma u otra, todos y cada uno de los personajes verán truncados sus planes de futuro: el principal confabulador de la trama, Rivadeneira, y sus cómplices, los nobles, serán apresados por mandato real; don Juan, en una suerte de justicia poética, será asesinado por una Jimena que vivirá el resto de sus días lamentándose por la muerte de su amado; don Álvaro perecerá ajusticiado meses después en el cadalso y el monarca Juan in quedará retratado como un gobernante torpe, incapaz de hacer frente a sus obligaciones como rey. La sentencia final de doña Jimena, «monarca de Castilla, llegáis tarde» (IV, 10, p. 76) con la que se cierra la obra y con la que Morán apela al espíritu crítico de los espectadores, así lo constata.

En definitiva, a la luz de todo lo anteriormente expuesto, podría concluirse que Los cortesanos de don Juan II es un drama que se adscribe a la perfección al grupo de teatro histórico político tan en auge en España durante la década de los treinta, a través del que los autores románticos tratan de mostrar a la opinión pública la necesidad de cuestionar determinadas actitudes políticas y de reflexionar acerca del desastre al que conduce el ansia irracional de poder. Jerónimo Morán se sirve teatralmente de la convulsión que vive la corte del rey Juan en 1453, de las conspiraciones de los cortesanos y nobles que fraguan en su seno el ajusticiamiento de Luna, para redactar y

\footnotetext{
${ }^{23}$ M. S. Catalán Marín, ob. cit., p. 166.
} 
llevar a escena el alegato liberal y anticarlista de su drama, en sintonía con una serie de piezas teatrales en torno al mismo conflicto - y con un trasfondo político similar-que se editan o estrenan coincidiendo con el fin de la primera guerra carlista.

\section{Bibliografía}

Alonso Cortés, N., Antología de poetas vallisoletanos modernos, Valladolid, Biblioteca Studium, 2014.

Catalán Marín, M. S., La escenografía de los dramas románticos españoles (1834-1850), Zaragoza, Prensas Universitarias de Zaragoza, 2003.

CARnero, G., «Temas políticos contemporáneos en el teatro español de los primeros años del siglo XIX», en E. Caldera (ed.), Teatro Politico Spagnolo del Primo Ottocento, Roma, Bulzoni, 1991.

Ceide Rodríguez, M., «El Romanticismo y la recuperación de la materia medieval: el caso de J. Morán», en R. Hernández Arias, G. Rivera Rodríguez, S. Cuba López y D. Pérez Álvarez (eds.), Nuevas perspectivas literarias y culturales (I CIJIELC). Vigo, MACC-ELICIN, 2016.

Flores Barrera, J. M. de, Cronica de D. Alvaro de Luna, Condestable de los Reynos de Castilla y de Leon, Maestre y Administrador de la Orden y Caballeria de Santiago, Madrid, Imprenta de D. Antonio de Sancha, 1784.

Mata IndurÁIN, C., «Los dramas históricos de Gertrudis Gómez de Avellaneda», en K. Spang (ed.), El drama histórico. Teoría y comentarios, Pamplona, EUNSA, 1998, pp. 193-213.

MoRÁn, J., Los cortesanos de don Juan II, drama histórico original en cuatro actos y variedad de metros, Madrid, Repullés, 1839.

Rey Hazas, A. y J. R. Muñoz Sánchez, El nacimiento del cervantinismo: Cervantes y el Quijote en el siglo XVIII, Madrid, Verbum Editorial, 2006.

Ribao Pereira, M., Textos y representación del drama histórico en el romanticismo español, Pamplona, EUNSA, 1999.

, «Prensa, actualidad y romanticismo español: el caso de Jerónimo Morán y la corte de Juan II de Castilla», en I. Rodríguez Moranta y D. Thion (eds.), Culture pour tous. Le rôle des médias dans la vulgarisation des savoirs, monográfico de Amnis. Revue de Civilisation Contemporaine Europes/Amériques, 14 (2015).

«Una relectura romántica de la corte: Los cortesanos de don Juan II, de Jerónimo Morán», en J. M. González Herrán et al., eds., La historia en la literatura del siglo XIX. Actas del Coloquio de la Sociedad Española del Siglo XIX, Barcelona, Universitat de Barcelona, 2017, pp. 651-660. 